科 学 通 报

\title{
W6Mo5Cr4V2 高速钢激光相变硬化机理
}

\author{
刘宁 邩宗钢 胡镇华 崔 崑 \\ 孔捷程 本 培 \\ (华中理工大学机械工程二系,武汉 430074) \\ (中国科学院固体物理研究所,合肥 230031)
}

\section{关链调 W6Mo5Cr4V2 高速钢、激光热处理、相变䂭化机理、超高硬度}

高速钢的激光热处理,采用熔融处理后, 硬度不高 ${ }^{[1-4]}$, 一般仍需后续常规淬、回火处理;而 采用相变硬化技术, 处理后可获得 HV1000 以上的超高硬度 ${ }^{[s-7]}$, 从而免除了后续的淬火工 艺, 并使高速钢的抗咬合性、耐磨性显著提高 ${ }^{[8]}$, 但硬化机理尚不清楚 ${ }^{[1}$. 本文用电镜、X 射线 衍射方法, 研究了 W6Mo5Cr4V2 高速钢激光处理获得超高硬度的机理, 以便为生产应用提供 理论依据。

\section{1 试验材料和方法}

试样尺寸及成分同文献 [4,6-8]. 试样经 $1220^{\circ} \mathrm{C}$ 淬火 $+560^{\circ} \mathrm{C} \times 1 \mathrm{~h}$ 三次回火常规处理 后, 表面进行了磷化处理. 激光处理在 JCS-033 数控激光热处理机上进行, 所用工艺参数 为功率 $1 \mathrm{~kW}$, 光斑直径 $4 \times 10^{-3} \mathrm{~m}$, 扫描速度 $40 \times 10^{-3} \mathrm{~m} / \mathrm{s}$. 用荷兰 PHILIPS PW1700 全 自动 $\mathrm{X}$ 射线衍射仪测定马氏体组织的轴比 $c / a$, 并对马氏体峰用 Warren-Averbach 傅氏分 析法测量了“显微畸变”和“枝镶尺寸”. 透射电镜观察在 $\mathrm{H}-800$ 型透射电镜上进行.

\section{2 试验结果和讨论}

大量电镜观察发现，激光相变硬化处理后的组织是直径为 $2 \mu \mathrm{m}$ 左 右 的 超 细晶 粒（图 1(a)), 晶内是细化的马氏体和残余奥氏体 (图 1(b)), 钢中未溶碳化物很少, 在 $3 \%$ 左右, 且 全部分布在原奥氏体晶界上(图 1(a),(c)), 这些未溶碳化物是 $\mathrm{M}_{6} \mathrm{C}$ 和 $\mathrm{MC}$ 型 ${ }^{[6,7]}$; 马氏体形态 是位错、孪晶在同一组织中共存, 极少出现典型板条位错马氏体或片状孪晶马氏体, 且具有相 近形貌的马氏体条片发育生长不完全, 尺寸很小(图 1(b), (c), (f)). 大量电镜观察发现, 与常 规淬火的马氏体组织相比, 激光相变硬化处理后组织中马氏体特征不明显具有普遍性,这一点 与文献 [9]的结论相一致.

可以认为在超快速加热条件下, 过热度极大造成相变驱动力 $\Delta G^{\alpha^{\prime \rightarrow r}}$ 很大, 从而使奥氏体 形核数目剧增，而瞬时加热后的瞬时奥氏体化时间使奥氏体来不及长大，因而产生直径 $2 \mu \mathrm{m}$ 左右的超细晶粒组织. 特殊形貌马氏体的存在, 反映了超快速加热过程中奥氏体内出现了极 大的碳浓度不均匀性, 使得含碳量相近的微观区域尺寸很小, 从形貌上看，具有相近形貌的马 氏体条片生长不完全, 尺寸也很小。晶粒和组织的细化必然使钢的强度、硬度提高.

钢的显微硬度及 X 射线等测量结果列于表 1. 由表 1 可见, 激光相变硬化处理组织中残 余奥氏体数量并不更多些,则应是超快速淬火冷却使 $M_{s}$ 点升高 ${ }^{[0]}$, 并使奥氏体的热稳定化现

1992-07-17 收稿，1993-03-15 收修改稿. 

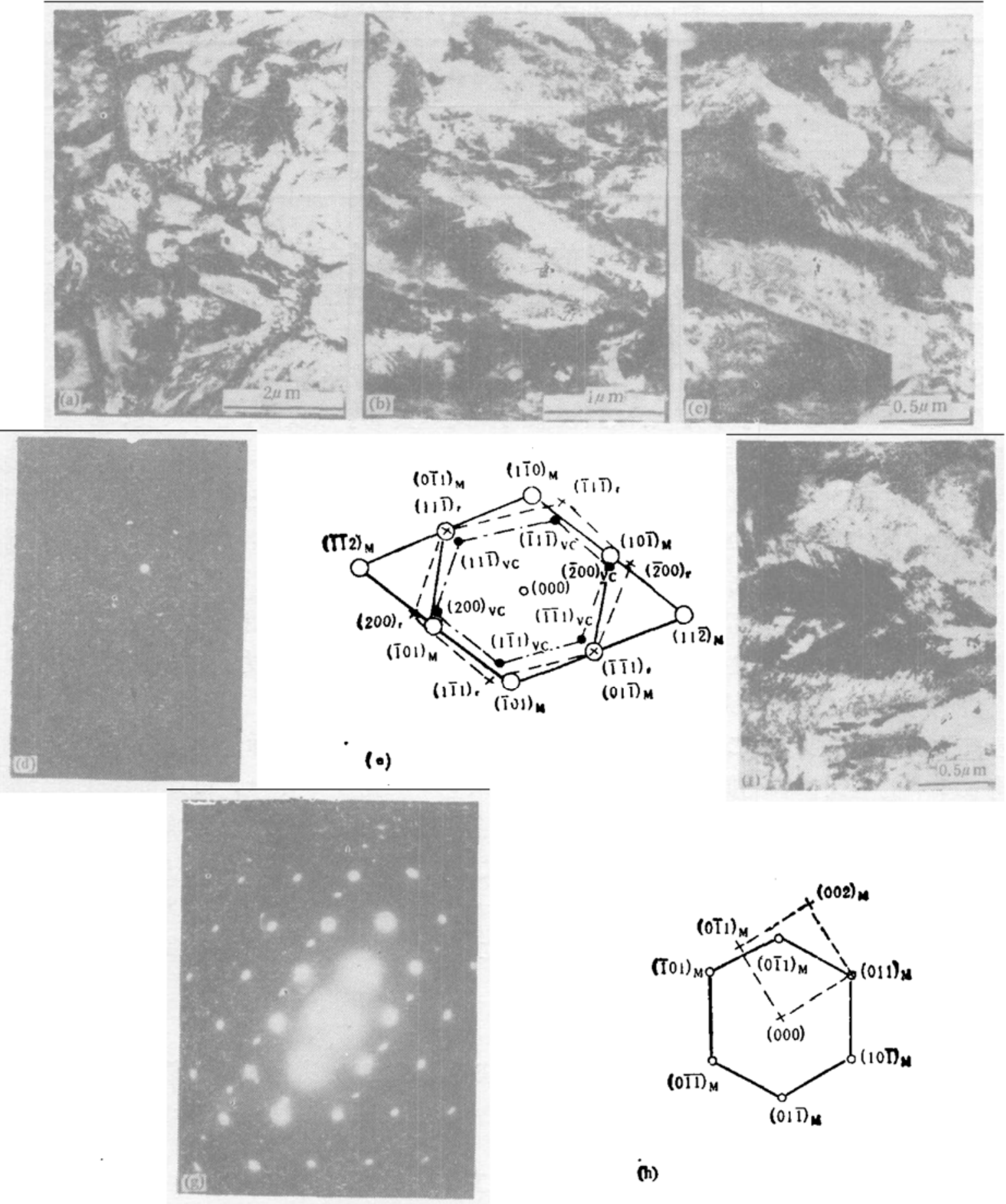

图 1 W6Mo5Cr4V2 高速钢激光淬火组织的 TEM 像

（a）明场，（b）明场，（c）明场， (d)、(c) 上部晶界处的衍射斑点，（e）、(d) 斑点的指标化，

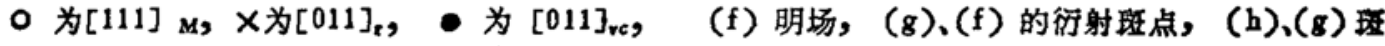
点的指标化, $O$ 为 $[111]_{M}, X$ 为 $[100]_{M}$

象降低所致. 残余奥氏体少时有利于获得高硬度。

由表 1 还可见,激光快速淬火使钢的“嵌镶尺寸”细化, “点阵畸变”程度大大增加. 目前, 有关宏观残余应力即第一类残余应力对钢的力学性能的影响方面的研究很多, 且结论已很明 确. 而在讨论 “点阵畸变”即第二类残余应力所导致的衍射线形的物理宽化时, 现有的定献所 涉及的大多是经冷加工后的试样的情况, 对淬火非经冷变形的试样所具有的衍射线形的物理 宽化机制提及甚少 ${ }^{[1]}$. 我们认为, 激光快速淬火使钢的“点阵畸变”程度增加即使第二类残余 
表 1 W6 M05 $\mathrm{Cr}_{4} \mathrm{~V} 2$ 高速钢试验结果

\begin{tabular}{|c|c|c|c|c|c|c|}
\hline 工 艺 & $\begin{array}{l}\text { 硬度 } H V 0.1 \\
(10 \mathrm{MPa})\end{array}$ & $\begin{array}{c}\text { 晶粒直径 } \\
(\mu \mathrm{m})\end{array}$ & $\begin{array}{c}\text { 残余奥氏体含量 } \\
(\%)\end{array}$ & $\underset{c / a}{\text { 马氏体轴比 }}$ & $\begin{array}{l}\text { 族铳块尺寸 D } \\
(\mathrm{nm})\end{array}$ & $\begin{array}{l}\text { 显徽畤变 } \\
(\%)\end{array}$ \\
\hline 激光相变硬化 & 1045 & 2 & 19.5 & 1.0275 & 7.999 & 0.539 \\
\hline $1220^{\circ} \mathrm{C}$ 常规淬火 & 810 & 11 & 20.5 & 1.0232 & 9.999 & 0.456 \\
\hline
\end{tabular}

应力增加的原因在于相变不同时性所导致的组织应力. 这是由于激光加热超快潓奥氏 体 化 时, 尚存有未溶的合金碳化物,使之材料的微区化学成分变得极不均匀, 且极短的奥氏体化时 间也使得已奥氏体化的组织中碳及合金元素来不及充分扩散均匀化. 在随后超快速淬火冷却 的相变过程中, 相变并非在同一温度下发生, 而是围绕宏观 (或平均相变温度) 相变点 $M_{s}$ 上下 波动而形成相变温度带 ( $M_{s}$ 带). 含碳量较低的奥氏体其 $M_{s}$ 点较高, 先行转变, 含碳量较高 的奥氏体其 $M_{s}$ 点较低, 滞后转变. 由于先行转变相的存在使之后转变的高碳马氏体的膨胀 受到约束,因而在相变组织间产生微观应力,使之转变相的晶面间距较之正常情况下的晶面间 距发生 $d \pm \Delta d$ 的变化, 引起 $\mathrm{X}$ 光衍射线形的物理宽化. 由于激光加热时奥氏体中具有相同含 碳量的区域尺寸范围很小, 故淬火时极难充分形成常见的板条位错马氏体和片状孪晶马氏体. 这在图 1 的电镜相片中可以清楚地看到. 反之, 由图 1 的电镜观察结果, 可推知组织中碳及合 金元素分布极不均匀, 而这又必然导致淬火后组织中的第二类残余应力增加, 可很好地解释激 光淬火使钢的“点阵畸变”大大增加的结果.

已有的研究 ${ }^{[11}$ 表明,第二类残余应力的大小对钢的强度、硬度指标无影响。

将表 1 中的马氏体轴比值代人文献 $[12]$ 中公式 $c / a-1+0.046 x$, 可算得含碳量分别约 为 $0.5 \%$ 和 $0.6 \%$; 可见, 激光处理固溶了更多的合金碳化物, 从而使马氏体的固溶碳量增加, 并进而使强度、硬度提高. 将表 1 中嵌镶尺寸值代入文献[13]中公式 $\rho-3 / D^{2}$, 可估算得位 错密度分别为 $3.0 \times 10^{12} 1 / \mathrm{cm}^{2}$ 和 $4.6875 \times 10^{12} 1 / \mathrm{cm}^{2}$, 其位错密度增量 $\Delta \rho=1.6875 \times 10^{12} 1 /$ $\mathrm{cm}^{2}$. 可见, 激光相变硬化处理使得马氏体组织的位错密度增加, 从而提高了钢的强度和硬度。

\section{3 结 论}

W6Mo5Cr4V2 高速钢经激光相变硬化处理获得 HV1000 以上超高硬度的主要原因是超 细化的晶粒、马氏体的高密度位错和高的固溶碳含量以及马氏体组织的进一步细化.

\section{参考文献}

[1] Strutt, P. R., Mater. Sci. Eng., 1980, 44(2):239.

[2] Kim, Y. W. et al., Metall. Trans., 1979, 10A(7):881.

[3] Kusinski, J., Metall. Trans., 1988, 19A(2):377.

[4] 刘守筂,金属学报, 1992, 28(8): A333.

[5]整鄂等,金属热处理, 1987,(11): 15.

[6] 刘宁等, 合肥工业大学学报, 1992,15(1): 56 .

[7] 刘宁符,金属热处理, 1992,(10): 8

[8] 刘宁等,金属热处理学报, 1992,13(3): 11 .

[9] 刘汭龙等,金属热处理学报, 1988,9(1): 64 .

[10] Donachie, S. J. et al., Metall. Trans., 1975, 6A(10):1863.

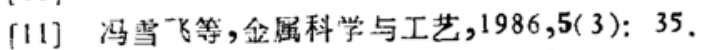

1:2\} Kurdjumov, G. V., Metall Trans., 1976, 7 A(7):999.

[13] 禾庆恩等,金属学报, 1983,19:3): B99. 